\title{
다발성경화증
}

\section{Multiple Sclerosis}

\author{
김 광 국 | 울산의대 신경과 | Kwang-Kuk Kim, MD \\ Department of Neurology, University of Ulsan College of Medicine \\ E-mail :kkkim@amc.seoul.kr
}

J Korean Med Assoc 2007; 50(3): 252 - 258

\section{Abstract}

Ultiple Sclerosis (MS) is the most common demyelinating disease affecting the central
nervous system of young adults living in western countries. The clinical suspicion of
demyelination, as a pathological process, is high when a young adult develops one or more
neurological episodes indicating a damage to white matter tracts within the central nervous
system, especially when the optic nerve, brainstem, or spinal cord is involved. The patient with
episodes disseminating in time, each of which can be attributed to demyelination, requires no
investigation prior to establishing the diagnosis of clinically definite MS, if the age of clinical
presentation falls between 20 and 50 years, if different anatomical sites within the central nervous
system have necessarily been affected on separate occasions, and if the clinical manifestation is
typical for MS. MS in Asian populations is characterized by selective and dominant involvement
of the optic nerve and spinal cords, as well as some incidence of brainstem lesion and symp-
toms. About 35 40\% of cases of MS in Korea are of this optico-spinal type. Optico-spinal MS
(OSMS) generally has a higher female-to-male ratio than conventional MS. OSMS is also
characterized by frequent relapses, severe disability, few brain lesions on MRI, and a very lower
incidence of oligoclonal bands in CSF. Neuromyelitis Optica (NMO) (Devic syndrome), which
causes severe optic neuritis (ON) and longitudinally extensive transverse myelits either with a
monophase or relapse-remitting pattern, is rare in Korean. NMO- IgG was reported to be helpful
for the diagnosis of early-stage NMO and differential diagnoses of MS.
Keywords : Demyelinating disease; Multiple sclerosis; Neuromyelitis Optica; NMO-lgG;
Opticospinal MS
핵 심 용 어: 말이집탈락병(탈수초성병); 다발성경화증; 시각신경척수염; 시각신경척수염항체(lgG);
시신경척수형다발성경화증

\section{서 론

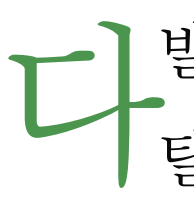 발성경화증은 중추신경계에 국한된 대표적인 말이집 탈락(탈수초)성 염증 질환이다. 아직 정확한 병리기} 전은 밝혀지지 않았지만 중추신경의 수초(myelin)에 대한
자가면역질환으로 알려져 왔다. 아시아인에서는 발병률이 상대적으로 낮고 주로 뇌병변으로 인한 증상을 호소하는 유 럽인과 북아메리카 백인보다는 처음 증상으로 혹은 반복되 는 증상으로 시신경계 병변으로 인한 시력저하, 시야장애와 척수염에 의한 상하지 마비 및 감각이상증, 대소변장애 등 


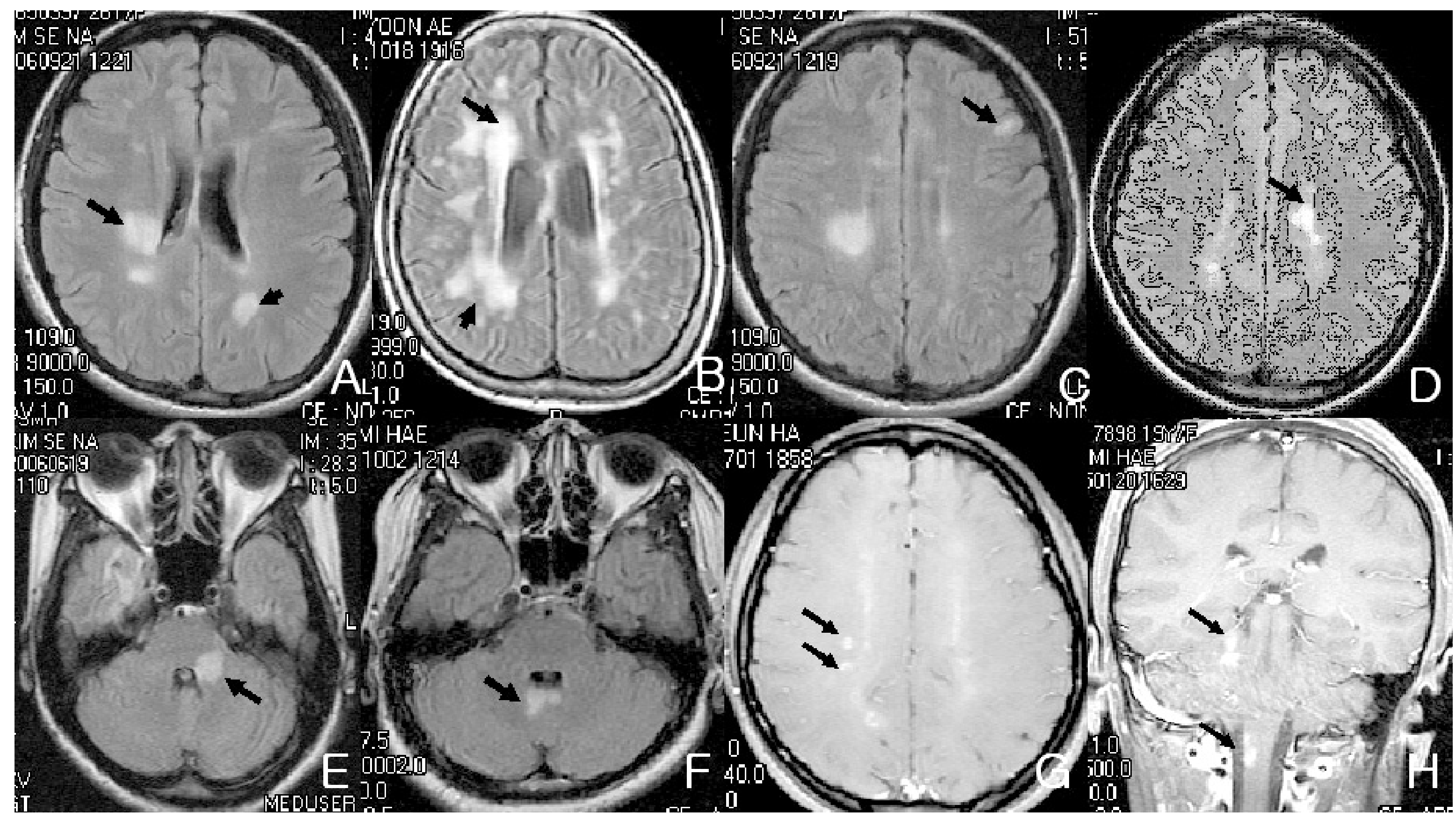

Figure 1. Multiple sclerosis lesions (arrows) depicted using $(A \sim F)$ fast FLAIR, and $(G, H) T 1$-weighted gadolinuim enhanced sequence

을 더 많이 자주 호소한다(1).

이런 유형의 다발성경화증은 뇌자기공명영상(MRI)에서 백인 다발성경화증 환자에서 흔히 볼 수 있는 뇌실주위, 인 접피질부위, 소뇌 등에서 말이집탈락(demyelination) 병변 이 발견되지 않고 시신경계나 경부 - 흥부 척수 부위에 병변 이 있어 별도로 시신경척수형 다발성경화증(optico-spinal multiple sclerosis, OSMS)(Table 1)으로 명명하기도 한다(1).

$60 \%$ 이상의 다발성경화증 환자는 두 차례 이상의 뇌병변, 시신경염, 척수염 등에 의한 재발-완화되는 과정을 거쳐 후유 뇌척수병변에 의한 장애를 나타내면서 서서히 진행되는 이차 성진행(secondary progressive)형으로 진행되며 30\%는 $2 \sim 3$ 차례의 재발 - 호전을 반복하다 더 이상 진행되지 않는 양 성(benign)형으로 남는다. 다발성경화증 환자의 $10 \%$ 내에서 재발-호전 등의 변화 없이 처음부터 지속적으로 진행되는 일 차성진행(primary progressive)형이나 심한 급성횡단성척수 염 및 시신경염이 동시에 혹은 반복적으로 재발되면서 상하지 마비 및 시각장애를 일으키는 시각신경척수염(neuromyelitis optica, NMO)(Table 2) 형태로 구분할 수 있다 $(2,3)$.

\section{증상 및 징후}

301명의 환자의 증상을 정리한 Swingler의 보고에서 가 장 많이 호소하는 순서로 나열하면 쇠약(weakness), 감각 증상, 운동실조증, 방광증상, 피로, 경련, 복시, 시력장애, 장 운동장애, 말더듬증, 어지럼, 안면통증, 기억력장애, 두통 순 이며 시작 증상으로는 감각이상증, 쇠약, 시력장애, 운동실 조증, 복시 등 시신경, 척수 및 뇌줄기 병변에 의한 증상을 호소하였다(4).

신경학적 검사에서 가장 많이 발견되는 징후는 시력 저하, 복부피부반사 소실, 진동감각 저하, 건반사항진, 색각장애, 상 지운동실조, 안구진탕, 근긴장항진, 주저-긴박뇨 등이다(4).

또한 증상과 징후로 추정된 가장 많이 연관된 뇌병변은 시신경계, 척수, 뇌줄기-소뇌, 뇌피질 순이다(4). 우리나라 다발성경화증 환자의 증상은 시신경척수형이 많기 때문에 쇠약, 감각이상, 방광증상, 시력장애, 장운동장애 등의 순으 로 많았다(5).

백인 환자들에서 주로 뇌병변, 소뇌-뇌줄기에 여러 병변 
Table 1. Diagnostic Criteria for opticospinal MS (1)

\begin{tabular}{l} 
Criteria for opticospinal MS \\
\hline 1. Clinically estimated main lesions are confined to the optic nerve \\
and spinal cord \\
2. Neither cerebellar nor cerebral symptoms \\
3. Minor brainstem signs are acceptable \\
4. At least one relapse ( $\geq$ two attacks)
\end{tabular}

이 생기는 전형적인 형의 다발성경화증과는 달리 시신경척 수형 다발성경화증(OSMS)은 주로 시신경과 척수에 병변이 있어 쇠약(weakness), 감각증상, 운동실조증, 방광증상, 경 련, 시력장애, 장운동장애 등의 증상을 호소한다.

뇌줄기 병변에 의한 경한 증상과 증후도 허용한다는 기준 (Table 1)에 의해 말더듬증, 어지럼 증상과 복시, 안진 등의 증후가 발견되기도 한다. 특히 여자 환자가 많으며 처음 증 상이 늦게 나타나지만 병이 지속되는 기간은 별 차이가 없 었다(6). 전 환자에 대한 시신경척수형(OSMS)의 비는 영국 (6\%)과 비교해서 일본(42\%)에서는 7배로 높았고(7) 서울아 산병원의 환자에서는 $33 \%$ 로 역시 유럽보다는 높았다(5). 말이집탈락 질환에 속하는 시각신경척수염(NMO)의 진단 기준은(Table 2) "한번 혹은 여러 차례의 시신경염과 적어 도 3 개 척추체를 초과하는 긴 횡단성 척수염이 동시에 혹은 시간을 두고 각각 재발이 발생할 때"로 정하였다(3).

\section{진단에 필요한 실험실적 자료}

\section{1. 올리고클론띠 (Oligoclonal Bands, OCBs)}

척수액과 혈청을 등전압초점맞추기로 검사하여 $\mathrm{IgG}$ 생성 이 중추신경내 척수액에서만 생성되는 것을 증명하는 검사 방법을 이용한다. 뇌척수액내 올리고클론띠는 백인의 다발 성경화증 환자에서 $90 \%$ 이상 양성으로 발견되어(8) 다발성 경화증의 보조진단적 가치가 높은 반면, 동양 환자에서는 $30 \%$ 정도 양성반응을 보이며 $(5,9)$ 시각신경척수염 $(\mathrm{NMO})$ 환자인 경우 $10 \%$ 미만에서 확인되어 상대적으로 진단가치 가 떨어진다.

\section{2. $\lg G$ 지표(Index)}

척수액과 혈청의 $\mathrm{IgG}$ 비를 척수액과 혈청의 알부민 비로 나
Table 2. Diagnostic Criteria for neuromyelitis optica (3) Diagnosis requires all absolute criteria and one major supportive criterion or two minor supportive criteria

\begin{tabular}{l} 
Absolute criteria \\
\hline 1. Optic neuritis \\
2. Acute myelitis \\
3. No evidence of clinical disease outside of the optic nerve or \\
spinal cord \\
Supportive criteria \\
Major \\
1. Negative brain MRI at onset \\
2. Spinal cord MRI with signal abnormality extending over \\
$\geq 3$ vertebral segments \\
3. CSF pleocytosis of $>50$ WBC/mm ${ }^{3}$ or $>5$ neutrophils $/ \mathrm{mm}^{3}$ \\
Minor \\
1. bilateral optic neuritis \\
2. severe optic neuritis with fixed visual acuity worse than \\
20/200 in at least one eye \\
3. Severe, fixed, attack-related weakness (MRC grade \\
$\leq$ in one or more limbs
\end{tabular}

눈 값으로 정의하며 뇌척수액내 과도한 $\operatorname{IgG}$ 생성을 증명하는 의미가 있으며 올리고클론띠와 같이 중추신경계의 면역반응 을 간접적으로 시사하는 의미가 있으나 특이성은 떨어진다.

\section{NMO-IgG (Neuromyelitis Optica-lgG)}

Aquaporin-4항원에 특이하게 반응하는 것으로 밝혀진 $\mathrm{NMO}-\operatorname{IgG}$ 항체(10)는 시각신경척수염 환자(85\% 이상)(11) 와 시신경척수형 다발성경화증 환자에서(63\%)(12) 높은 민 감도를 보였다. 아주 심한 다발성 뇌병변을 지닌 시신경척 수형과 대표적인 다발성경화증 환자에서도 발견되어 $(3,12)$ 앞으로 시신경척수형 MS와 시각신경척수염의 많은 환자를 대상으로 한 민감도/특이도의 연구 결과가 필요하다.

\section{임상적으로 확실한 다발성경화증 환자의 MRI 소견}

\section{T2 강조 뇌|MRI (13)}

뇌실 주위에서 95\% 환자에서 병변이 발견된다. 백질 주 변부의 국소적 병변이 주로 많이 관찰되나 깊은 백질부에도 국소적으로 혹은 융합성으로 관찰된다(Figure 1A, 1B). 뇌 피질에 아주 인접한 부위에도 $70 \%$ 이상의 환자에서 병변이 
발견된다(Figure 1C). 뇌혈관질환에서 잘 관찰되지 않는 뇌량(corpus callosum) 병변도 시상영상에서 잘 관찰된다(Figure $1 D)$. 뇌줄기 병변은 뇌척수액과 인접한 부위와 4실 및 중간뇌수도관(cerebral aqueduct) 부위에서 관찰된다(Figure 1E, 1F).

\section{T2 강조 척수 $\mathrm{MRI}$}

한 척추체(vertebral body)의 길이보 다 길게 보이는 척수 병변은 드물며, 척수 전단면의 일부에만 국한되고 비대칭적이 며, 쐐기모양으로 표면과 연결되어 보일 수도 있다(Figure 2). 초기에는 부종이, 시간이 지나면 위축이 관찰된다. 뇌병변 이 심하지 않은 원발성진행성 형태의 환 자에서 척수 병변이 많이 보이는 경우가 있다.

\section{3. 조영제(Gadolinium) 증강 MRI}

대부분의 조영증강 병변은 뇌백질부, 피질인접부, 피질밑 심부에서 잘 관찰된

다(Figure $1 \mathrm{G}, 1 \mathrm{H}$ ). 조영증강은 평균적으로 4 6주 지속되 나(14) 1 주간 지속되는 경우도 있다(15). 3개월 이상 지속 되는 경우는 매우 드물기 때문에 지속적으로 조영 증강되는 종양이나 신경사르코이드증(neurosarcoidosis)과 감별하 기 위하여 재촬영이 필요할 수도 있다. 초기 재발-회복되는 환자에서 조영증강병변은 잘 관찰되나 최근 재발이 없는 이 차성진행성 형의 환자(16)와 일차성진행성 형의 환자에서 조영증강된 병변은 잘 관찰할 수 없다(17).

\section{T1 hypointense 병변}

$\mathrm{T} 1$ 강조영상은 뇌실질부 손상을 보기 위해 촬영한다(18). 작은 혈관 질환과 노화된 뇌병변과는 달리 다발성경화증 환 자의 만성 T2 병변의 $20 ~ 30 \%$ 는 T1 강조영상에서 지속적으 로 T1 hypointense 병변으로 보이는 특성이 있다(19). 만
성 T1 hypointense 병변은 T1 isointense 병변보다 축삭손 상과 더 연관이 있다. 초기 T1 hypointense 병변은 간혹 T1 조영증강 병변으로 보일 수 있으며 정상으로 회복되는 경우 적어도 수 개월 걸린다(20).

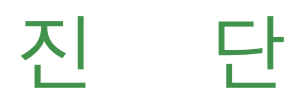

다발성경화증 환자의 진단은 매우 까다롭다. (1) 환자가 호소하는 증상이 뇌병변에 의한 것인지, (2) 진찰과 뇌 MRI, 유발전위검사 등으로 여러 뇌병변들에 의한 것인지, (3) 뇌 면역 질환으로 인한 실험실적인 결과(MRI, 뇌척수액검사, IgG index, Oligoclonal band, NMO-IgG 항체검사 등)를 설명할 수 있는지, (4) 다른 질환으로는 임상증상과 발병양 상, 유사한 실험실적인 결과를 설명할 수가 없는지 등에 대 
Table 3. McDonald criteria for multiple sclerosis: categories of multiple sclerosis (21)

\begin{tabular}{|c|c|}
\hline Clinical presentation & Additional data needed for diagnosis of multiple sclerosis \\
\hline $\begin{array}{l}\text { Two or more attacks; } \\
\text { Objective clinical evidence of two or more lesions }\end{array}$ & None \\
\hline $\begin{array}{l}\text { Two or more attacks; } \\
\text { Objective clinical evidence of one lesion }\end{array}$ & $\begin{array}{l}\text { - Dissemination in space demonstrated by MRI } \\
\text { or } \\
\text { - Up to two MRI detected lesions consistent with multiple sclerosis plus positive } \\
\frac{\text { cerebrospinal fluid }}{\text { or }} \\
\text { - await further clinical attack implicating a different site }\end{array}$ \\
\hline $\begin{array}{l}\text { One attack; } \\
\text { Objective clinical evidence of two or more lesions }\end{array}$ & $\begin{array}{l}\text { - Dissemination in space demonstrated by MRI } \\
\text { or } \\
\text { - Second clinical attack }\end{array}$ \\
\hline $\begin{array}{l}\text { One attack; } \\
\text { Objective clinical evidence of two or more lesions } \\
\text { lesions(monosymptomatic presentation; clinically } \\
\text { isolated syndrome) }\end{array}$ & $\begin{array}{l}\text { - 1) Dissemination in space demonstrated by MRI or } \\
\text { 2) Up to two MRI detected lesions consistent with multiple sclerosis plus positive } \\
\text { cerebrospinal fluid and Dissemination in time demonstrated by MRI } \\
\text { or } \\
\text { - second clinical attack }\end{array}$ \\
\hline $\begin{array}{l}\text { Insidious neurological progression suggestive of } \\
\text { multiple sclerosis }\end{array}$ & $\begin{array}{l}\text { - Positive cerebrospinal fluid And Dissemination in space demonstrated by } \\
\text { 1) nine or more T2 lesions in the brain or } \\
\text { 2) two or more lesions in the spinal cord or } \\
\text { 3) four to eight brain lesions plus one spinal cord lesion } \\
\text { or } \\
\text { - Abnormal visual evoked potential associated with four to eight brain lesions, or } \\
\text { with fewer than four brain lesions plus one spinal cord lesion demonstrated by } \\
\text { MRI and Dissemination in time demonstrated by MRI or Continued progression } \\
\text { for } 1 \text { year }\end{array}$ \\
\hline
\end{tabular}

한 명확한 대답을 할 수 있을 때 가능하다.

임상에서 중추신경계의 말이집탈락 질환의 유형은 다음 세가지로 분류된다. (1) 환자의 증상과 증후가 중추신경계 의 각각 다른 부위의 병변이 말이집탈락으로 재발-회복을 반복하면서 생겼을 때(임상적으로 확실한 혹은 거의 확실 한 다발성경화증), (2) 확실치 않은 병력과 전형적인 말이집 탈락으로 인한 독립된 증상이 최근 생겼을 때, (3) 말이집탈 락에 의한 것으로 여겨지는 증상이 지속적으로 진행될 때로 구분할 수 있다.

최근 제시된 McDonald 등이 고안한 진단기준(21)(Table 3)의 주된 변화는 "특유한 공간적(Table 4), 시각적 확산 (Table 5)을 뜻하는 뇌병변의 MRI 소견이 다발성경화증 진 단에 중요한 요소가 된다" 는 것이다. 예를 들면 말이집탈락 성 뇌병변에 의한 임상증상과 증후가 한 차례 있었을 때 특 유한 시각적, 공간적 뇌병변의 MRI 소견이 있으면 재발된 뇌병변에 의한 임상증상과 증후가 없더라도 진단할 수 있 다. 또한 처음 증상 발생 30 일 이상 지난 후에 처음 증상과
같은 뇌병변 부위에 재발이 의심될 때, 특유한 공간적 뇌병 변의 MRI 소견이 있을 때나 Oligoclonal band가 뇌척수액 소견에서 보이면서 공간적 뇌병변의 MRI 소견이 있을 때 진 단할 수 있다(13).

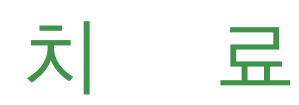

1. 급성 시신경, 척수염, 의식장애나 뇌기능장애를 나타내는 심한 뇌병변이 있을 경우 초기에 Methyl prednisol $1,000 \mathrm{mg}$ 을 정맥주사로 3일에서 5일간 사용하고 경구 스 테로이드 약으로 용량을 줄이면서 2주 정도 사용 후 중단 한다. 지속적으로 적은 용량으로 사용하는 것은 재발 방 지에 도움이 되지 않는다는 보고가 있다(22).

2. 시토카인(cytokine) 조절제인 Interferon Beta(IFN- $\beta$ ) 를 5 16년간 사용하여 재발-회복 형태의 다발성경화증 환자의 재발횟수를 줄이고 뇌척수의 누적 병변의 정도를 줄여 병의 진행을 억제하는 효과가 있다고 보고하였다 
Table 4. Diagnostic Criteria for MS: MRI evidence for dissemination in space (21)

\begin{tabular}{l} 
Three of the following: \\
\hline 1. One or more gadolinium enhancing lesions or nine or more T2 \\
hyperintense lesions if there is no gadolinium enhancing lesion \\
2. One or more infratentorial lesions \\
3. One or more juxtacortical lesions \\
4. Three or more periventricular lesions
\end{tabular}

Notes: i) one spinal cord lesion can substitute for one brain lesion; ii) two T2 lesions plus cerebrospinal fluid oligoclonal bands also constitute evidence for dissemination in space

(22). 현재 우리나라에서도 MS의 예방적 목적으로 IFN- $\beta$ 의 처방이 이루어지고 있으며 IFN- $\beta$ 의 사용에 대한 내 용은 다음과 같다.

(1) 베타페론(인터페론 베타-1b, 레비프프리필드) 주사 제, 코팍손(Copaxone) 주사제 등을 사용한다. 주로 면 역조절약(immunomodulating agent)으로 Cytokine 의 분비 등을 조절하거나 T-helper 2 cell의 기능을 향상시키는 약으로 재발-회복(relapsing-remitting) 형이나 이차성진행(secondary progressive)형에 사 용한다.

i ) 용량: 베타페론 8million IU subcutaneous, 2 일 마다 1 차례씩 1달에 15 번

· 레비프 interferon-beta1a 44ug, subcutaneous, 1주일에 3번, 1 달에 12차례

ii ) 기간은 효용성이 없다고 판정할 때까지 사용한다 (적어도 5년 이상).

iii) 중지기준은 (1) 신경과 전문의가 진찰하여 12 개월 이내 2회의 심한 뇌척수 병변으로 인한 증상이 재 발될 때, (2) 6개월에 걸쳐 뇌척수병변이 진행되어 증상이 악화되었을 때, (3) 6개월간 지팡이를 사용 해도 보행 능력이 나빠져 걸을 수 없을 때로 정하 였다.

(2) Mitoxantrone, Cyclophosphamide, Azathioprine, Tem-sirolimus 등의 세포독성(cytotoxic) 재제도 연구 중임.

(3) 단클론항체(monoclonal antibodies) 재제인 Natalizumab(상품명 Tysabri), Daclizumab(상품명 Zeno-
Table 5. Diagnostic Criteria for MS: MRI evidence for dissemination in time (21)

1. If a first scan is $>3$ months after the onset of the clinical event, the presence of a gadolinium enhancing lesion is sufficient to demonstrate dissemination in time, provided that it is not at the site implicated in the original clinical event. If there is no enhancing lesion at this time, a follow-up scan is required. A new T2 or gadolinium enhancing scan within 3 months then fulfils the criteria for dissemination in time.

2. If the first scan is performed $<3$ months after the onset of the clinical events, a second scan done 3 moths or more after the clinical event showing a new gadolinium enhancing lesion provides sufficient evidence of dissemination in time. If no enhancing lesion is seen at this second scan, a further scan e3 months after the first scan that shows a new T2 or gadolinium enhancing lesion will suffice.

$\mathrm{pax}$ 제제도 제한적인 범위 내에서 FDA 공인을 받아 시판될 것으로 추정된다.

\section{참고문헌}

1. Kira J. Multiple sclerosis in the Japanese population. The Lancet Neurology 2003;2:117-127.

2. Devic E. Myelite subaigue compliquee de neurite optique. Bull Med 1894:8:1033-1034

3. Wingerchuk DM, Hogancamp WF, O'Brien PC, Weinshenker BG. The clinical course of neuromyelitis optica (Devic's syndrome). Neurology 1999;53:1107-1114.

4. Swingler RJ, Compston DAS. The clinical features of multiple sclerosis in south east Wales. Q J Med 1992;83:325-337.

5. Kim KK. Optico-spinal multiple sclerosis and neuromyelitis optica. J Kor Neurol Assoc 2006;24(S):66-69.

6. Kira J, Kanai T, Nishimura Y, Yamasaki K, Matsushita S, Kawano Y, Hasuo K, Tobimatsu S, Kobayashi T. Western versus Asian types of multiple sclerosis: immunogenetically and clinically distinct disorders. Ann Neurol 1996;40:569-574.

7. Shibasaki $H$, McDonald WI, Kuroiwa YJ. Racial modification of clinical picture of multiple sclerosis; comparison between British and Japanese patients. J Neurol Sci 1981;49:253-271.

8. Yu YL, Woo E, Hawkins BR, Ho HC, Huang CY. Multiple sclerosis amongst Chinese in Hong Kong. Brain 1989;112:14451467.

9. Yu YL, Woo E, Hawkins BR, et al. Multiple sclerosis among Chinese in Hong Kong. Brain 1989;112:1445-1467.

10. Lennon VA, Kryzer TJ, Pittock SJ, Verkman AS, Hinson SR. IgG marker of optic-spinal multiple sclerosis binds to the aquaporin-4 water channel. JEM 2005;202:473-477.

11. Lennon VA, Wingerchuk DM, Kryzer TJ, Pittock SJ, Lucchi- 
netti CF, Fujihara K, Nakashima I, Weinshenker BG. A serum autoantibody marker of neuromyelitis optica: distinction from multiple sclerosis. Lancet 2004;364:2106-2112.

12. Nakashima I, Fujihara K, Miyazawa I, Misu T, Narikawa K, Nakamura $\mathrm{M}$, et al. Clinical and MRI features of Japanese MS patients with NMO-lgG. JNNP 2006

13. Compston A, ed. McAlpine's Multiple Sclerosis: The diagnosis of multiple sclerosis, 4th ed. Churchill Livingston, 2006:351388.

14. Miller DH, Rudge P, Johnson G, Kendall BE, Macmanus DG, Moseley IF, Barnes D, McDonald WI. Serial gadolinium enhanced magnetic resonance imaging in multiple sclerosis. Brain 1988;111:927-939.

15. Cotton F, Weiner HL, Jolesz FA, Guttmann CR. MRI contrast uptake in new lesions in relapsing-remitting MS followed at weekly intervals. Neurology 2003;60:640-646.

16. Kidd D, Thorpe JW, Kendall BE, Barker GJ, Miller DH, McDonald WI, Thompson AJ. MRI dynamics of brain and spinal cord in progressive multiple sclerosis. J Neurol Neurosurg Psychiatry 1996; 60:15-19.

17. Thompson AJ, Kermo AG, Wicks D, MacManus DG, Kendall $B E$, Kingsley DP, McDonald WI. Major differences in the dynamics of primary and secondary progressive multiple sclerosis. Ann Neurol 1991;29:53-62.
18. van Waesberghe JH, Kamphorst W, De Groot CJ, van Walderveen MA, Castelijns JA, Ravid R, Lycklama a Nijeholt GJ, van der Valk $\mathrm{P}$, Polman $\mathrm{CH}$, Thompson AJ, Barkhof F. Axonal loss in multiple sclerosis lesions: magnetic resonance imaging insights into substrates of disability. Ann Neurol 1999;46:747754.

19. Uhlenbrock D, Sehlen S. The vaule of T1-weighted images in the differentiation between MS, white matter lesions and subcortical arteriosclerotic encephalopathy (SAE). Neuroradiology 1989:31;203-212.

20. Bagnato F, Jeffries N, Richert ND, Stone RD, Ohayon JM, McFarland HF, Frank JA. Evolution of $\mathrm{T} 1$ black holes in patients with multiple sclerosis imaged monthly for 4 years. Brain 2003; 126:1782-1789.

21. McDonald WI, Compston A, Edan G, Goodkin D, Hartung HP, Lublin FD, McFarland HF, Paty DW, Polman CH, Reingold SC, Sandberg-Wollheim M, Sibley W, Thompson A, van den Noort S, Weinshenker BY, Wolinsky JS. Recommended diagnostic criteria for multiple sclerosis: guidelines from the International Panel on the diagnosis of multiple sclerosis. Ann Neurol 2001;50:121-127.

22. Compston A, ed. McAlpine's Multiple Sclerosis: Diseasemodifying treatments in multiple sclerosis, 4th ed. Churchill Livingston, 2006:729-810.

\section{김 병 준 (성균관의대 신경과)}

다발성경화증은 서양에서는 비교적 흔한 신경과 질환이지만 본 논문에서 밝힌 바와 같이 동양 사람의 다발성경화증은 빈도가 낮고 증상도 서양인과 차이를 보인다. 이러한 차이가 인종적 차이인지 혹은 전혀 다른 질환인지에 대한 결론은 아직 유보된 상태이다. 이러한 의미에서 최근에 알려진 NMO-lgG는 감별진단의 목적으로 큰 주목을 받고 있다. McDonald 진단기준은 조기 진단을 통하여 인터페론 치료와 같은 예방적 치료를 좀 더 빨리 시작하고자 하는 목적으 로 $\mathrm{MRI}$ 를 기초로 만들어진 진단기준이다. 최근에는 시간적, 공간적 파종의 기준과 척수병변에 대한 기준을 개정한 revised criteria를 이용하여 좀 더 유연한 진단기준을 이용하고 있다(Ann Neurol 2005;58:840-846). 인터페론 치료는 가능한 조기에 시작하여 재발이장성 경과를 보이는한 지속하는 것이 권장되고 있다. 